\title{
Cervical Ventral Epithelial Cyst Treated by Anterior Corpectomy
}

\author{
-Case Report-
}

\author{
Kenta Fujimoto, Shozo KaWAI, Yoshihiro TANAKA, Yasuharu WATABE, \\ Shiro CHITOKU, Takatoshi FuJimoto, Takeshi FuJI*, and Tsuneo SHIGI*
}

\author{
Departments of Neurosurgery and *Orthopedic Surgery, \\ Osaka Prefectural Hospital, Osaka
}

\begin{abstract}
A 15 -year-old boy presented with a cervical ventral epithelial cyst manifesting as intractable cervical pain. Neurological examination revealed weakness of his left grasp and increased deep tendon reflexes. The anterior approach was selected because the lesion was located directly ventral to the spinal cord. $\mathrm{He}$ underwent C4-5 anterior corpectomy and subtotal resection of the cyst wall. He made a good recovery without additional deficits. Most previously reported cases have been treated using the posterior approach despite the ventral location of the lesion. The anterior approach offers a safer and more effective means of treating such lesions because it allows direct access to the lesion without manipulation of the spinal cord.
\end{abstract}

Key words: spinal cyst, epithelial cyst, anterior approach, corpectomy

\section{Introduction}

Spinal epithelial cysts are rare congenital lesions that are characterized histologically by epithelium composed of mucin-producing columnar cells, and underlying connective tissue. ${ }^{151}$ The relationship of this lesion to the enteric or respiratory epithelium is debatable. $^{10,11,15)}$ The usual location is in the ventral region of the spinal cord, and most previous cases were treated surgically via the posterior approach. ${ }^{1-6,9-12,17)}$

We report a patient with a cervical ventral epithelial cyst who was treated successfully using the anterior approach, and discuss the associated benefits and risks.

\section{Case Report}

A 15-year-old boy presented with a complaint of severe neck pain that increased with neck extension. Neurological examination revealed weakness of the left grasp and increased deep tendon reflexes. Radiography of the cervical spine showed dilatation of the spinal canal at the C4-5 level. Magnetic resonance (MR) imaging revealed a ventral cystic mass at this location (Fig. 1). The spinal cord appeared to be compressed dorsally and atrophic. The cyst had signal characteristics similar to those of cerebrospinal fluid, without enhancement using gadolinium-diethylenetriaminepenta-acetic acid (GdDTPA). The preoperative diagnosis was an epithelial or arachnoid cyst.

Surgical treatment used the anterior approach for direct access to the lesion. Under general anesthesia, he was placed in the supine position on the operating table, and a halo-vest was applied. A skin incision was made along the medial border of the left sternocleidomastoid muscle. Blunt dissection was performed, and the vertebral bodies were exposed. Corpectomy ( $20 \mathrm{~mm}$ wide) of $\mathrm{C}-4$ and $\mathrm{C}-5$ was performed with a high speed drill. The inferior margin of C-3 and the superior margin of C-6 were drilled out to facilitate bone grafting. The posterior longitudinal ligament was removed carefully and the dural sac was exposed. The dura was bulging an- 


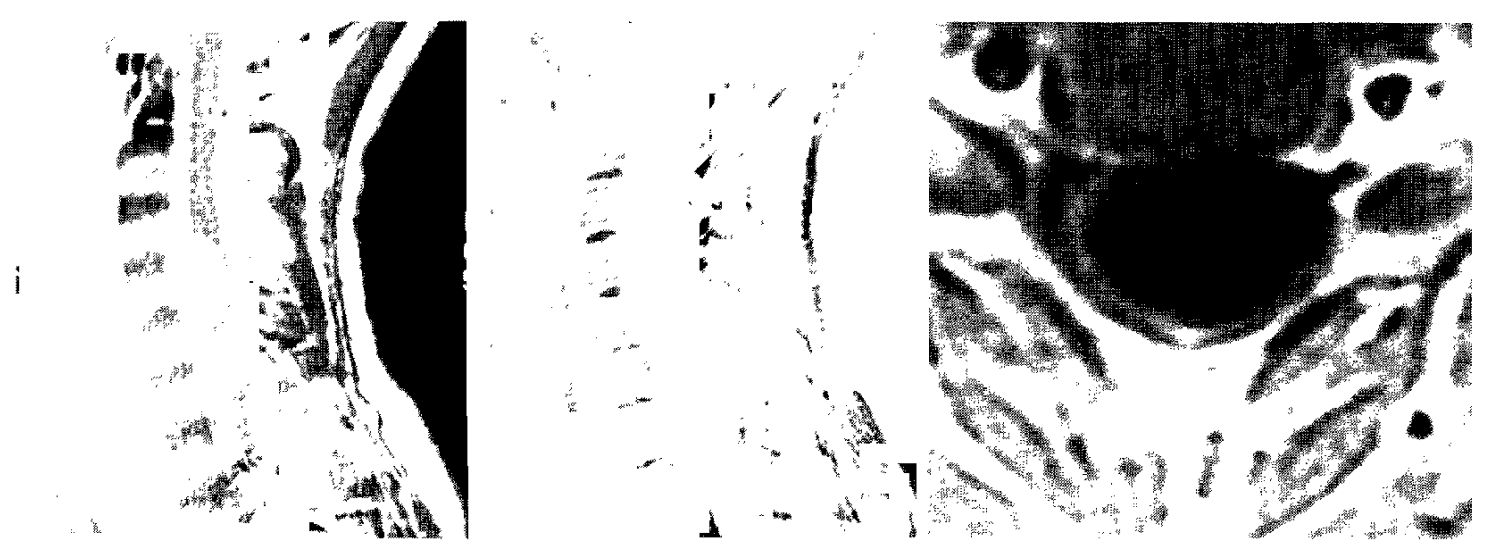

Fig. 1 MR images showing the cervical ventral cyst compressing the severely atrophic cord dorsally. The cyst demonstrated signal characteristics similar to cerebrospinal fluid. left: $\mathrm{T}_{1}$-weighted image, sagittal; center: $\mathbf{T}_{2}$-weighted image, sagittal; right: $\mathrm{T}_{1}$-weighted image, axial.

teriorly but did not pulsate. A dural incision was made and the arachnoid membrane was dissected. A cyst with thin, white, and semitransparent walls containing clear, yellowish fluid was found anterior to the spinal cord (Fig. 2 upper). The cyst was excised except for a small tissue fragment that tightly adhered to the ventral aspect of the spinal cord (Fig. 2 middle). The spinal cord began to pulsate immediately after resection of the cyst. Anterior spinal fusion was performed using an autogenous fibular strut bone graft (Fig. 2 lower). Intraoperative monitoring of somatosensory evoked potentials and spontaneous ventilation revealed no changes.

Histological examination of the surgical specimen revealed a single layer of mucin-producing, columnar, non-ciliated epithelium (Fig. 3). Immunohistochemical analysis showed these cells were positive for carcinoembryonic antigen.

Postoperatively, he did well and had no new neurological deficits at discharge. Postoperative radiography of the cervical spine revealed that the grafted bone was seated at a suitable position (Fig. 4). MR imaging 3 weeks postoperatively showed satisfactory decompression of the spinal cord, but the spinal cord atrophy was not totally resolved (Fig. 5). Although his neck pain had improved, the mild weakness of his left grasp and left-sided hyperreflexia persisted. Postoperative immobilization was achieved with a halo-vest for 2 months. He recovered well and MR imaging showed no recurrence of the lesion for 2 years.

\section{Discussion}

Spinal epithelial cysts occur most often in the cervi- cal ventral segment, but most previous cases were treated using the posterior surgical approach (Table 1). ${ }^{1-6,9-12,17)}$ The surgical exposure of lesions involving the ventral spinal cord is technically difficult. The posterior approach through a standard laminectomy provides adequate access only to lesions involving the dorsal or dorsolateral pial surface of the spinal cord. This approach requires some manipulation of the spinal cord to reach the ventral lesion, and recurrence of the cyst and severe myelopathy are two possible complications. ${ }^{7,11,12)}$ Spinal instability after multilevel laminectomy is well documented in children. Yasuoka et $a l .^{19)}$ reported a $46 \%$ incidence of spinal deformity following multilevel laminectomy in children, and a 6\% incidence in patients aged 15-24 years. Yaşargil et al ${ }^{18)}$ considered that lesions could be removed from the dorsal, dorsolateral, lateral, contralateral ventral, and dorsal aspects of the spinal cord using a posterolateral approach via unilateral hemilaminectomy. Martin et al. ${ }^{8)}$ described a technique for exposing the ventrolateral quadrant of the spinal cord through an extended posterolateral approach, which requires unilateral removal of the facet and pedicle, and the lateral surface of the anterior spinal artery is at the medial limit of this approach. Recurrence has occurred in patients treated by the posterior approach. ${ }^{5,11,12)}$ Only Crockard and $\mathrm{Sen}^{2)}$ have reported a ventrally located C-2 neurenteric cyst removed totally via the transoral anterior approach. In our case, the lesion was located just ventral to the spinal cord.

The anterior approach provides direct visualization of the ventral surface of the spinal cord on both sides of the lesion, thus minimizing cord manipulation and allowing extensive and total resection of the 

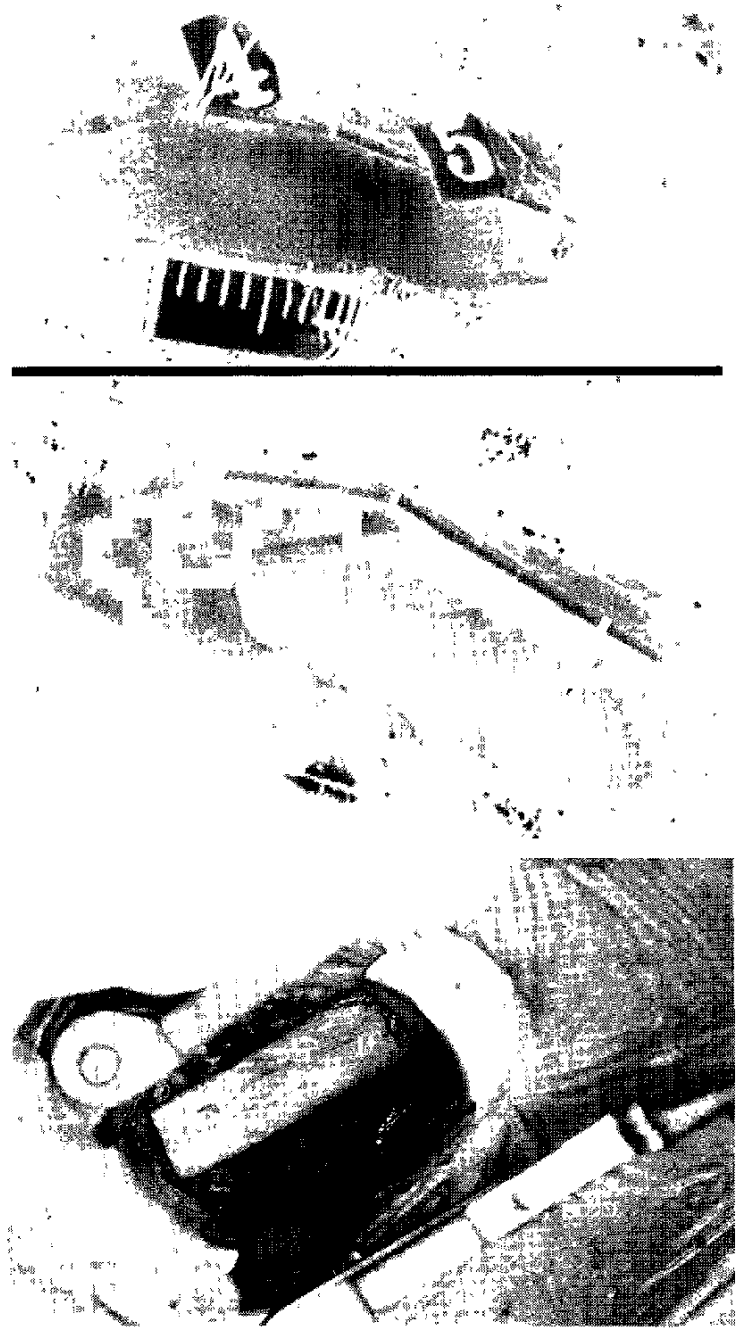

Fig. 2 Intraoperative photographs. upper: The vertebral bodies were removed subtotally to expose the cyst. The cyst wall was white and semitransparent. middle: The cyst wall was resected widely. arrow: severely atrophic spinal cord. lower: Anterior spinal fusion using an autogenous fibular strut bone graft.

cyst wall, but requires subsequent vertebral fusion. In addition, accelerated bone degeneration may occur at the sites of the mobile segments above and below the graft site. Long-term immobilization is also necessary, and there are occasional graft bone complications. ${ }^{14,16)}$ The transoral approach is restricted to lesions in the upper cervical spine, whereas the anterior approach can expose the lower $\mathrm{C}-2$ to upper $\mathrm{T}$ 1 levels. Lesions located at lower levels require the transthoracic approach. The extent of longitudinal

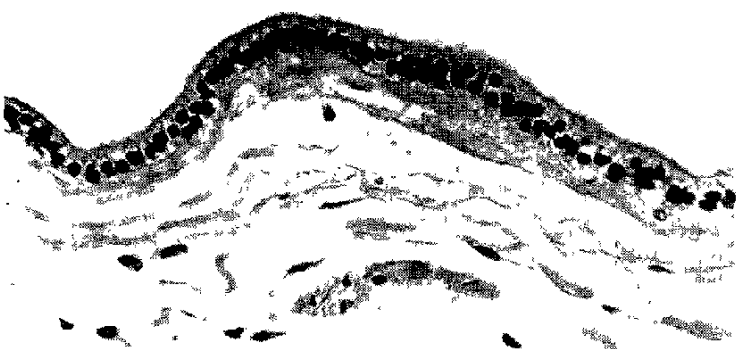

Fig. 3 Photomicrograph of the cyst wall showing a single layer of columnar non-ciliated epithelial cells which secret mucin. HE stain, $\times 300$.

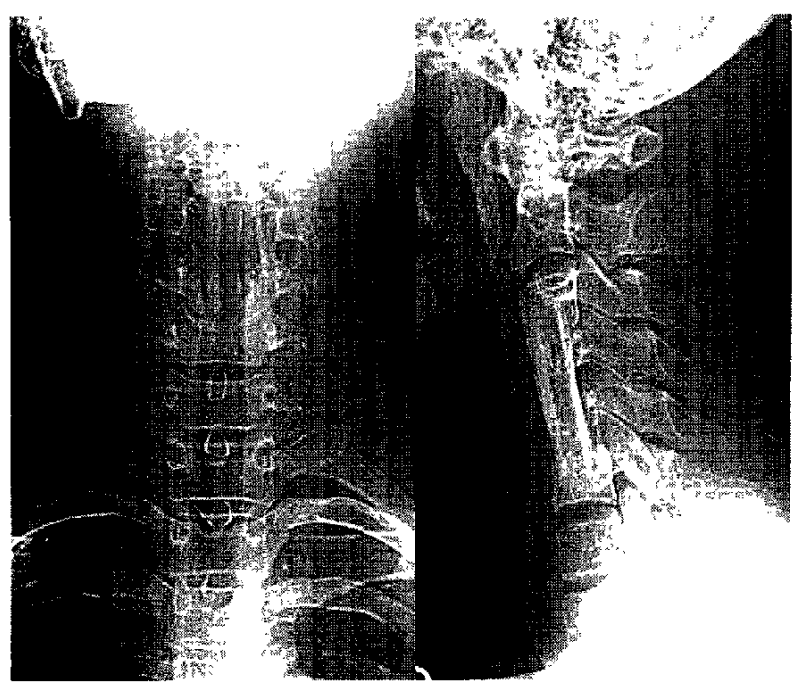

Fig. 4 Postoperative cervical radiographs showing the grafted bone seated at a suitable position.
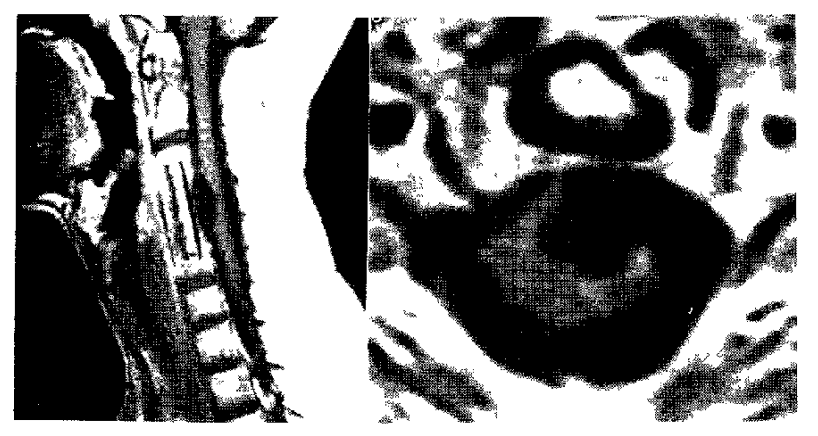

Fig. 5 Postoperative MR images showing the cyst had disappeared and the cord was decompressed, but not fully restored due to atrophy. 
Table 1 Previous cases of spinal epithelial cyst (including enterogenous and neurenteric cysts)

\begin{tabular}{|c|c|c|c|c|c|}
\hline Author (Year) & $\begin{array}{l}\text { Age/ } \\
\text { Sex }\end{array}$ & Location & Symptom & $\begin{array}{c}\text { Opera- } \\
\text { tion }\end{array}$ & Outcome \\
\hline Fabinyi and Adams (1979) & $54 / \mathrm{F}$ & C-1 (ventral) & neck pain & $P$ & excellent \\
\hline In et al. $(1979)^{6}$ & $21 / \mathrm{F}$ & $\mathrm{T} 1-2$ (ventral) & $\begin{array}{l}\text { gait disturbance, } \\
\text { back pain }\end{array}$ & $\mathbf{P}$ & excellent \\
\hline Hashimoto et al. $(1981)^{5)}$ & $54 / F$ & L4-5 & hydrocephalus & $\mathrm{P}$ & $\begin{array}{l}\text { recurrence } \rightarrow \\
\quad \text { reoperation }\end{array}$ \\
\hline $\begin{array}{l}\text { D'Almedia and Stewart } \\
(1981)^{3)}\end{array}$ & $40 / \mathrm{M}$ & C3-4 (ventral) & scapular pain & $\mathrm{P}$ & excellent \\
\hline Takemi et al. $(1984)^{17)}$ & $12 / \mathrm{F}$ & C-3 (intramedullary) & tetraparesis & $\mathrm{P}$ & excellent \\
\hline Agnoli et al. $(1984)^{11}$ & $39 / \mathrm{F}$ & C3-4 (lt) & paresis (upper) & $\mathbf{P}$ & good \\
\hline Matsushima et al. (1985) & $8 / \mathrm{F}$ & C5-T1 (ventral) & tetraparesis & $\mathbf{P}$ & excellent \\
\hline Miyagi et al. $(1988)^{10)}$ & $11 / \mathrm{F}$ & C3-5 (ventral) & neck pain & $\mathbf{P}$ & excellent \\
\hline Morita et al. $(1990)^{11)}$ & $11 / \mathrm{M}$ & C3-7 (ventral) & paresis (upper) & unknown & recurrence \\
\hline Crockard and Sen $(1991)^{2)}$ & $40 / \mathrm{M}$ & CVJ (ventral) & neck pain & A & $\begin{array}{l}\text { good } \rightarrow \text { posterior } \\
\text { fusion }\end{array}$ \\
\hline \multirow[t]{2}{*}{ Osenbach et al. (1992) ${ }^{12)}$} & $32 / \mathrm{F}$ & C2-3 (ventral) & not described & $\mathbf{P}$ & good \\
\hline & $7 / \mathrm{M}$ & C2-3 (ventral) & quadriparesis & $\mathbf{P}$ & recurrence $\rightarrow$ shunt \\
\hline Present case & $15 / \mathrm{M}$ & C4-5 (ventral) & neck pain & A & excellent \\
\hline
\end{tabular}

A: anterior approach, CVJ: craniovertebral junction, P: posterior approach.

vertebrectomy is restricted to three segments. ${ }^{13,14)}$

We consider that the anterior approach allowed safer and more effective treatment of our patient, and suggest that it is suitable for the treatment of ventrally located cervical intradural lesions.

\section{References}

1) Agnoli AL, Laun A, Schonmayer R: Enterogenous intraspinal cysts. $J$ Neurosurg 61: 834-840, 1984

2) Crockard $\mathrm{HA}$, Sen $\mathrm{CN}$ : The transoral approach for the management of intradural lesion at the craniovertebral junction. Neurosurgery 28: 88-98, 1991

3) D'Almedia AC, Stewart DH: Neurenteric cyst. Neurosurgery 8: 596-599, 1981

4) Fabinyi GCA, Adams JE: High cervical spinal cord compression by an enterogenous cyst. $J$ Neurosurg 51: 556-559, 1979

5) Hashimoto $T$, Nakamura $N$, Yasue M, Fuse $T$, Funahashi K, Sekino H: Intraspinal neurenteric cyst associated with increased intracranial pressure. $\mathrm{Neu}$ rol Med Chir (Tokyo) 21: 1183-1189, 1981 (in Japanese)

6) In S, Shigemori M, Ishii C, Kusano N, Takagi S: A case of intraspinal neurenteric cyst. No Shinkei Geka 7: 1095-1099, 1979 (in Japanese)

7) Long DM, McAfee PC: Atlas of Spinal Surgery. Baltimore, Williams \& Wilkins, 1992, $344 \mathrm{pp}$

8) Martin NA, Khanna RK, Batzdorf U: Posterolateral cervical or thoracic approach with spinal cord rotation for vascular malformations or tumors of the ventrolateral spinal cord. J Neurosurg 83: 254-261, 1995

9) Matsushima T, Fukui M, Egami H: Epithelial cells in a so-called intraspinal neurenteric cyst. Surg Neurol 24: 656-660, 1985

10) Miyagi $K$, Mukawa J, Mekaru $S$, Ishikawa $Y$, Kinjo $\mathrm{T}$, Nakasone S: Enterogenous cyst in the cervical spinal canal. Case report. J Neurosurg 68: 292-296, 1988

11) Morita $Y$, Kinoshita $K$, Wakisaka S, Makihara S: Fine surface structure of an intraspinal neurenteric cyst. Neurosurgery 27: 829-833, 1990

12) Osenbach RK, Godersky JC, Traynelis VC, Schelper RD: Intradural extramedullary cysts of the spinal canal. Neurosurgery 30: 35-42, 1992

13) Otani K: Sekitsui-Shujutsu No Jissai. Tokyo, IgakuShoin, 1989, 192 pp (in Japanese)

14) Rengachary SS, Redford JB: Partial median corpectomy for cervical spondylotic myelopathy, in Wilkins RH, Rengachary SS (eds): Neurosurgery Update 2. New York, McGraw-Hill, 1991, pp 356-359

15) Russell DS, Rubinstein LJ: Pathology of Tumours of the Nervous System, ed 5. London, Edward Arnold, $1989,704 \mathrm{pp}$

16) Schmidek HH, Smith DA: Anterior cervical disc excision in cervical spondylosis, in Schmidek HH, Sweet WH (eds): Operative Neurosurgical Techniques. Orlando, Grune \& Stratton, 1988, pp 1327-1342

17) Takemi K, Kubo S, Ibayashi N, Ikeda M, Ohta $T$, Yonezawa T: A case of cervical intramedullary neurenteric cyst. No Shinkei Geka 12: 539-543, 1984 (in Japanese)

18) Yaşargil MG, Tranmer BI, Adamson TE, Roth P: Unilateral partial hemilaminectomy for the removal of extra- and intradullary tumors and AVM's. $A d v$ Tech Stand Neurosurg 20: 113-132, 1993 
19) Yasuoka S, Peterson HA, MacCarty CS: Incidence of spinal column deformity after multilevel laminectomy in children and adults. $J$ Neurosurg 57: 441445,1982
Address reprint requests to: K. Fujimoto, M.D., Department of Neurosurgery, Osaka Police Hospital, 10-31 Kitayama-cho, Tennoji-ku, Osaka 543, Japan. 